\title{
XVI. A few additional practical observations on the wire-gauze safety-lamps for miners. With some evidence of their use
}

\section{Sir Humphry Davy}

To cite this article: Sir Humphry Davy (1816) XVI. A few additional practical observations on the wire-gauze safety-lamps for miners. With some evidence of their use , Philosophical Magazine Series 1, 48:219, 51-59, DOI: 10.1080/14786441608637610

To link to this article: http://dx.doi.org/10.1080/14786441608637610

曲 Published online: 27 Jul 2009.

Submit your article to this journal $₫$

Џll Article views: 4

Q View related articles $\llbracket$ 
land purchased of him at the two ends of Loch Oich, our transactions relative to the purchase of land have been terminated.

The amount of rent to be paid by us for the Redcastle quarry is to be determined under the direction of the court of session by William Fraser Tytler, esq. sheriff depute of the county of Inverness.

Accounts. The amount of our expenditure to the end of April 1816, appears to have been five hundred and ninety-four thousand ponds; twenty-five thousand pounds in full of the grant of the last session of parliament is now payable to us at His Majesty's Hxoliequer.

The account inserted in the Appendix is similar to all our preceding accounts; and the series is in such form as to embrace an extensive classification, and always to show the expenditure of the preceding twelvemonth, as well as of the total expenditure to the present time.

Mr. Telford's accounts and vouchers have been examined and passed by our accountant to the 12th day of August last; every part of our expenditure which does not pass through Mr. Telford's hands, is paid by ourselves, and andited under the direction of the Lords Commissioners of the Freasury.

Chardes Abbot.

N. VansitTart.

$\operatorname{Man} 17,1810$.

W. Grant.

Castrlireagh.

Meliville.

Binning.

Charies Grant.

1. H. BRowne.

XVl. A few additional practical Observations on the WireGauze Safety-Lamps for Miners. With some Evidence of their Use. By Sir Humphry Davy.

I

HAVE already published an account of the researches which led nie to discover that explosion and flame are incapable of passing through tubes and apertures, which are nevertheless very permeable to both light and air, and I. have described several contrivances for lighting coal-mines, in which inflammable air is disengaged, all founded on the same principle of security;

The lamp which has been found most convenient for the miner, is that compesed of a cylinder of strong wire +gauze fastened round the flame by a screw, and in which the wick is trimmed by a wire passing through a safe aperture.

Lamps of this construction have been commonly used in the D 2 
most dangerous mines in England for nearly five months, during which time no aecident has happened, and no inconvenience occurred.

Since I first published the account of the wire-gauze safe-lamp, I have made a number of experiments on flame, which have led to some new philosoplical views of this curious and inportant sulject, and to sone practical results, which I hope will be useful to the ininer : these last will form the subject of the following pages.

1 find that donble cylinders of wire-gauze, so arranged that the wires are parallel to each other, occasion very little loss of light, and rery much diminish the heat when the fire damp alone is burning within the cylinder; so that with double cylinders I have never observed the wire-gauze to become red hot. The double cylinder lamp, therefore, is preferable to the single one, whenever it is necessary to preserve a light for a long time in a highly explosive atmosphere, and it has likewise twice the strength of the single cylinder lamp.

If oojections, which have been made, probably by persons who had never seen the lamps, against the weakness of the wire, had really been valid, it would be easy to double the thickness of it, or to have treble, or even quadruple folds of wire, with bars perfeetly parallel. Layers of wire-gauze, for instance, of 25,26 , and 27 apertures to the inch in the cylinder of the common size, when arranged with a little care, intercept very little more light than a single layer.

I have had two lamps made of cylinders of copper perforated with numerous small apertures; but they are more expensive than cylinders made of copper wire-gauze.

I have hat a lamp made of double wire-gauze with an exterior copper chimney, which can be raised or lowered, so as to consume larger or smaller quantities of fire-damp. This lamp, I find, may be made to burn in a highly explosive atmosphere without producing considerable heat, for any length of time ; and it offers a convenient form of a lainp for destroying the fire damp.

It does not appear, from Mr. Buddle's communications, that the iron wire rusts in common use : should this be found to be the case in certain mines, copper wire may be used; the additional expense of this material is trifing ; and even wire plated with silver would not be so costly as to be an object in the price of the lamp. In the double cylinder lamp, the copper wire will never become red hot; and I lave had lamps made in which the inner cylinder was of iron and the outer one of copper wire.

Whenever a single wire lamp is made to burn in a very explosive stmosphere, the heat soon arrires at its maximum, and then diminishos; and the idea of the wires buming out, is shown to 
be unfounded; the carbonaceous matter produced from the deeomposition of the oil, tends not only to prevent the oxidation of the metal, but likewise revives any oxide already formed; and this coaly matter, when the fire-damp is burning in the lamp, choaks the upper apertures of the cylinder, and gradually diminishes the heat, by diminishing the quantity of gas consumed.

In my early inquiries on this subject, I thought that some vitreous incombustible composition might be used as a coating to prevent the rusting of the wire, and I made some experiments on this subject. I find that a fusible compound of boracic acid and the earth called baryta, answers the purpose of a coating very well; and if in any case experience should prove that such an application is necessary, it may be easily made.

It is obvious, that as long as the principle of security (which is to admit no aperture in a lamp of more than $\frac{1}{2} \sigma$ of an inch square) is preserved, the construction may be almost infinitely varied, and the fire-damp may be burned throughout the whole of a cylinder, or inflamed at certain surfaces only, and the light transmitted from other surfaces through born, or mica, or glass. I long ago had a lamp made of glass, in which the fire-damp bnrnt round the wick only, from a circular surface of wire-gauze, and which, in an explosive mixture, produced very little more heat than in the common atmosphere; but the facility with which glass is broken, and horn and mica injured, prevents me from. recommending any lamps in which these substances are used for the common purposes of the miner.

I have tried a chimney of brass capped with a double wiregauze cylinder, having two-thirls of its circumference opposite the flame open, and covered with wire-gauze. This, in an explosive mixture, produced very little heat, though it gave a tolerable light, and by increasing the surfaces impenneable, or by diminishing those permeable to air, the heat may be reduced in any degree*.

Whatever construction is adopted, too much attention cannot be paid to the form of the screw by which the cylinder or chimney is fastened to the lamp; it ought to be strong and deep, and to consist of at least three turns.

When the fire-damp is inflamed in the wire-gauze cylinders, coal dust thrown into the lamp burns with strong flashes and

* The Rev. John Ilodgson, whose zeal and activity in prombting the objects of these researches I canoot praise too highly, has had a lamp made upon this plan, having a thick plate of glass in a metallic chimney opposite a wire-gauze feeder, in which the supply of air is regulated by neans af a slider. I found a model which he sent me to answer very well; the only objection is, the chance of the glass being broken by a fall, or by a drop of ater when hot. 
scintillations. It appears that the miners were at first alarmed by an effect of this kind produced by the dust naturally raised during the working of the coals. I have made a numbrr of experiments on this subject; but though I have repeatedly thrown coal dust, powdered rosin, and witch meal, through lamips burning in more explosive mixtures than ever occur in coal mines, and though I have kept these substances floating in the explosive atmosphere, and heaped them upon the top of the lamp when it was red hot, yet $I$ never could communicate explosion by means of them. Phosphorus or sulphur are the only substances which can produce explosion by being applied to the outside of the lamp; and sulphur, to produce the effect, must be applied in large quantities and blown upon by a current of fresh air.

It will be unnecessary to caution the workmen against heaping sulphur, or gunpowder, or pyrites, which afford sulphur by distillation, upon their lamps; and such dust from these substances as can float in the atmosphere cannot produce inflammation; for minute particles of ignited solid matter have no power of inflaming the fire-damp; and I liave repeatedly blown fine coal dust mixed with minute quantities of the fiuest dust of gunpowder through the lamp burning in explosive mixtures without any cammunication of explosion : and supposing danger with respect to gunpowder, the steel-mill must be much more liable to inflame that substance than the wire-gauze lamp: and the double cylinder lamp offers perfect security against the inflammation of any matter that can ever exist in coal mines.

In adopting from 30 to 26 apertures to the inch (from 900 to 67,6 in the square inch) and wires of from $\frac{1}{50}$ to $\frac{1}{4} \frac{1}{6}$. of an inch in thickness, even single lamps are secure in all atmospheres of fire-damp; and double cylinder lamps are perfectly safe under all circumstances even in atmospheres made explosive by coal gas, which, from the quantity of olefiant gas it contains, is much more inflammable than fire-damp. When indeed a strong current of coal gas is driven from a blow-pipe, so as to make wire-gauze of 676 apertures strongly red hot in the atmosphere, the flame from this pipe may be passed through it whilst it is strongly red hot; but this is owing to the power which wires strongly ignited possess of inflaning coal gas * and they have no such effect on genuine fire-damp ; and a stream of gas burning in the atmosphere acting on a small quantity of matter, is entirely different from an explosive mixture, which is uniform within the lamp.

* Olefrant gas contains twice as much charcoal as light carburetted hydrogen, and is much more easily decomposed by heat; the density of its flame, as I shall show on a future occasion, depends upon solid inatrer produced by its decomposition in the process of combustion, and which becomes ignited; and the same circumstance hulds good of all fames affording intense light. 
In a case where human life is concerned, and by which human happiness may be affected, 1 have thought it right to take notice of the most trivial and insignificant objections, even when they have arisen from ignorance, or have been prompted by malevolence; but I do not think it necessary to name the individuals by whom they have been made, for I would willingly consign to forgetfulness those who do not deserve to be remeubered.

The evidence of the use of a practical discovery is of most value when it it is furnished by practical men. I shall therefore annex two communications, which $l$ am sure will have due weight with all persons who are aequainted with the northern collieries; and my motive for publishing them is the hope of inducing the coal owners in other parts of the island to lose no time in adopting these simple methods of preserving their workmen from danger*.

H. D.

\section{A Letter on the practicul Application of the Wire-gauze Sufe- lamp, from JoH B BuddiE, Esq. to Sir H. DAvy.}

Walls-end Colliery, Newcastle, 1st June, 1816.

SIR,-After having introduced your safety-lamp into general use in all the collieries under my clirection, where inflarhmable air prevails; and after using them daily in every variety of explosive mixture for upwards of three months, I feel the highest possible gratification in stating to you, that they have answered to my entire satisfaction.

The salety of the lamps is so easily proved, by taking them into any part of a mine charged with fire-damp, and all the explosive gradations of that dangerous element, are so easily and satisfactorily ascertained by their application, as to strike the minds of the most prejudiced with the strongest conviction of their high utility; and our colliers have adopted them with the greatest eagerness.

In the practical application of the lamps, scarcely any difficulty has occurred. Those of the ordinary working size, when prepared with common cotton wick and the Greenland whale oil, burn during the collier's shift, or day's work of six hours, without requiring to be replenished; and the safety trimmer answers the purpose of cleaning, raising, and lowering the wick completely.

The only inconvenience experienced arises from the great quantity of dust, produced in some situations by working the coal, closing up the meshes of the wire-gauze, and obscuring the light;

- Models of the double cylinder lamp, which I recommend in all collicries where explosive mixtures are common, as well as models of the single lamp, may be had of Mr. Newman, Lisle-street, Leicester-sqquare, London. 
but the workmen very soon removed this inconvenience by the application of a small brush.

We have frequently used the lamps where the explosive mixture was so high as to heat the wire-gauze red hot ; hut on examining a lamp which has been in constant use for three months, and occasionally salbjected to this degree of heat, I cannot perceive that the gauze cylinder of iron wire is at all impaired. I haye not, however, thought it prudent, in our present state of experience, to persist in using the lamps under such circumstances, because I have observed, that in such situations the particles of coal dust, floating in the air, fire at the gas burning within the cylinder, and Ay off in small luminous sparks. This appearance, I must confess, alarmed me in the first instance ; but experience soon proved that it was not dangereus. As it is, however, passible that some other light combustible substance, eapable of inflaming at a red heat, may occasionally float in the atmosphere of the mine, I have thought it prudent, for the present at least, to discontinue the use of the lamps where the gauze is subject to that degree of heat, especially if for a length of time at once.

Our colliers have found it most convenient to hang the star tionary lamps from small wooden pedestals; but on observing, that where the sides of the lamps have been suffered to come in contact with the pedestals, the wood is charted to a considerable depth by the heat of the lamps; I have thought it right to use small iron pedestals inste:t of the wooden ones.

Beside the facilities afforded by this invention to the working of coal mines abounding in fire-damp, it has eriabled the directors and superintendants to ascertain with the utmost precision and expedition, both the presence, the quantity, and the correct situation of the gas. Instead of creeping inch by inch with a candle, as is usual, along the galleries of a mine suspected to contain fire-damp, in order to ascertain its presence, we walk firmly on with the safe lamps, and with the utmost confidence prove the actual state of the mine. By observing attentively the several appearances upon the flame of the lamp, in an examination of this kind, the cause of aceidents which have happened to the most experienced and cautious miners is completely developec ; and this has bitherto becn, in a great measure, matter of mere conjecture.

When the discharge of inflammable air is regular, and the density of the atmosphere coutinues uniform, the firing point may. be judged of, and approached with safety by a common candle. But when the discharge of inflammable air is irregular, or the atmosphere is in an unsettled state, a degree of uncertainty and danger attends the experiment of ascertaining the state of a mine.

With 
With the safe-lamp, however, it is reduced to the utmost certainty, the actual presence and position of the gas is not only ascertained with the greatest precision, but also every alteration of circumstance or position is distinctly perceived.

By placing a lamp near the spot where a quantity of inflammable air is issuing, and mixing with the circulating current of atmospherical air to the firing point, it will be seen that very remote canses frequently produce pulsations in the atmosphere of the mine, which occasion the gas to fire at naked lights ; thus showing clearly the instability of the element with which we have to deal, and the reason why so many explosions have occurred where lights have not approached the place where the gas was lodged within a considerable distance.

Objections have been made by some who have not had experience of the lamps, to the delicacy of the wire-gauze, mider the apprehension that it may be very soon impaired by the flame within the cylinder. Of this, however, I have no reason to complain, as, after three months constant use, the gauze has not, in the hands of careful workmen, been perceptibly injured by the action of the flame; but the outer top gauze of one or two of Newman's making has been worn through by the friction of the rivet* on the bottom of the swivel, to which the finger ring is fastened ; but this only happened to the lamps used by the wastemen, whose business it is to travel daily in the various avenues of the mines, for the purpose of keeping the passage for the current of air free from obstructions: nothing of the kind has happened to the stationary lamps used by the colliers. In short, I do not apprehend that the gauze can be injured by any ordinary cause without being observed in time sufficient to prevent accidents; and that we have no danger to apprehend, except from the gross negligence of some heedless individual, or an accident of a very unusual description occurring to injure the gauze.

I find that I have extended my letter to a greater length than I intended; but I trust, Sir, that you will excuse me for having gone so much into detail, as I feel peeuliar satisfaction in dwelling upon a subject which is of the utmost importance not only to the great caluse of humanity, and to the mining interest of this country, but also to the commercial and manufacturing interests of the United Kingdom: for I feel convinced that by the happy invention of the safe-lamp, large proportions of the coal mines of the empire will be rendered available, which otherwise might have remained inaccessible-at least without an invention of similar utility, it could not have been wrought without much loss of the mineral, and risk of life and capital.

* This riret is now fixed. II. $D$. 


\section{Olservations on Wire-gauze Safeity-lamps for Miners.}

It is not necessary that $I$ should enlargeupon the national advantages which must necessarily result from an invention calculated to prolong our supply of mineral coal, because 1 think them obvious to every reflecting mind; but 1 cannot conclude without expressing iny highest sentiments of admiration for those talents which have developed the properties and controlled the power of one of the most dangerous elements which human enterprise has hitherto had to encounter.

\section{I have the honour to be, \&c. \&c. \\ To Sir H. Dar'y. JoHN BUDDLE.}

\section{Extract of a Letter from Mr. PEILE to Sir H. Davy.}

Collierv Office, Whitehaven, 6th July, 1816.

1 TAKE the liberty of adding a further statement on your invaluable safe-lamps, in the Whitehaven collieries belonging to the earl of Lonsdale, since the furst application of them in February last.

With us, the general use of the lamps in consequence of the good state of our ventilation is confined to leading workings, or trial drifts; and in two of these, lately going on in one of the pits unusually infected with fire-damp, and which previously were lighted by'means of steel-mills, we applied the lamps with great confidence and security.

In May last in these drifts an extraordinary discharge of firedamp burst from the pavement of the mine, and the ventilation being at that time unavoidably obstructed, the atmosphere became so charged with fire-damp as to be nearly throughout an explosive mixture. In this situation we derived the unspeakable benefit of light from the lamps, and, notwithstanding the explosive state of the mixture, with the most perfect safety.

In several other places in the collieries the lamps sre used with the same confidence: yet the discharge of fire-damp being moderate, they are not much exposed to explosive mixtures.

In all the workings showing the least appearance of fire-damp, the niners are supplied with lamps, and are particularly cautioned to use them on first entering when beginning to work, where, being satisfied of security, they occasionally resort to candles afterwards. This application of the lamp alone, is of the greatest utility, and prevents many slight explosions, and the miners from being burned; hesides superseding the necessity of depending on the judgenent or discrimination of any individual to prove the existence of the fire-damp; as in the old method, by the candle flame:

From the repeated proofs made with the lamps, we cannot too strongly express our confidence in their security.

By experiment, a pint of oil, value six-pence, will about sup- 
ply a lamp for six days, the ordinary time of a man's working, so that they are cheaper than candles.

If my humble testimony can in any degree promote the speedy use of the lamp in other places, it will give me great pleasure.

To Sir H. Davy. I remain, \&c. John Peile.

XVII. Extract of a Letter from Dr. OLBers, F.R.S. of Bremen, respecting a New Comet; with an Account of a Work of Professor Bessel. Communicated by a Correspondent.

A fter a long silence $I$ profit by the permission which you once gave me to address you in German, not being able to express myself readily in English, though I read the larguage without difficulty. My present object is to request a favour of you, which may give you some trouble, but which I hope the importance of the subject will induce you to grant me :-it is, that you would undertake to collect subscriptions for a work of Professor Bessel, of Königsberg, of which the prospectus is inclosed. I am willing to hope that an undertaking so essential for the advancement of astronony will be particularly encomraged in England, especially as it is entirely founded on the observations of your incomparable countryman Bradley. According to the present course of exchange, the price of the book will not exceed about a guinea and a half; and it will be printed as soon as a sufficient number of subscribers shall be found to afford a reasonable prospect of the repayment of the expenses.

I discovered a comet last year on the 6th of March, and gave immediate notice of the discovery to Dr. Herschel, as well as in the public papers. This comet was observed in Germany until the 25 th of August; and it is very remarkable for the shortness of the period of its revolution. Several of vur astronomers, and in particular Mr. Nicolai, now Director of the Observatory of Manheim, have calculated its motions in an elliptical orbit; and the results of their calculations agree extremely well with each other; but none of them has exhibited greater diligence and address in the inquiry than Professor Bessel. These are his elements, determined for the 26th April 1815 :

Time of the peribelion, $18 \mathrm{i} 5$ April 25.998674 , mean time at Paris. Longitude of the ascending node..... $83^{\circ} 2 s^{\prime} 33 \cdot 63^{\prime \prime}$

Inclination of the orbit...........44. $24^{\circ} 54.59^{\prime \prime}$

Distance of the perihelion from the node $65^{\circ} 33^{\prime} 22 \cdot 29^{\prime \prime}$

Logarithm of the shortest distance .... 0.0838109

Eccentricity................ 0.93121968

Greater semi-axis, or mean distance . $17 \cdot 63383$

Period .................... 74.04913: Motion direct.

The 